\title{
Insights for Conservation and Utilization: Reconstruction of China's Natural Resources Management System
}

\author{
Yonghuan $\mathrm{Ma}^{1,2}$, Chuguo $\mathrm{Wu}^{1,2}$, Hui Lin ${ }^{2,3, *}$, Baorong Huang ${ }^{2,3}$, Liyang $\mathrm{Su}^{2,3}$ \\ ${ }^{1}$ Information Center, Ministry of Natural Resources, People's Republic of China, Beijing, China \\ ${ }^{2}$ Key Laboratory for the Land and Resources Strategic Studies, Ministry of Natural Resources PRC, Beijing, China \\ ${ }^{3}$ Institutes of Science and Development, Chinese Academy of Sciences, Beijing, China

\section{Email address:} \\ yhma@infomail.mlr.gov.cn (Yonghuan Ma),cgwu@infomail.mlr.gov.cn (Chuguo Wu), linhui@ casisd.cn (Hui Lin), \\ huangbaorong@casisd.cn (Baorong Huang), suliyang@casipm.ac.cn (Liyang Su) \\ ${ }^{*}$ Corresponding author
}

\section{To cite this article:}

Yonghuan Ma, Chuguo Wu, Hui Lin, Baorong Huang, Liyang Su. Insights for Conservation and Utilization: Reconstruction of China's Natural Resources Management System. International Journal of Science, Technology and Society. Vol. 6, No. 3, 2018, pp. 52-62. doi: $10.11648 /$ j.ijsts.20180603.11

Received: May 5, 2018; Accepted: June 5, 2018; Published: August 21, 2018

\begin{abstract}
China's ecological civilization construction has marched into the New Era. As an important part of the ecological civilization system, the natural resource management system is the basic system in the ecological civilization system. Based on the problem and goal-oriented research method and with the international experience as a reference, this paper has put forward the firm concepts of respecting nature, adapting to nature and protecting nature based on the current backward concepts in China's natural resource management, the current problems of inadequate management system and incomplete management institution, adhered to the concepts of development and system based on the unity of development and protection and built a complete natural resources system which is made up of "Two Key Basics, Three Major Processes and Four Main Guarantees". In order to adapt to the requirements of China's natural resource asset management system and natural resource supervision system reforms, this paper has designed the reform paths of natural resource asset management and natural resource supervision system to realize the smooth process of natural resource management.
\end{abstract}

Keywords: Ecological Civilization, Natural Resource, Management System, Management Institution, Reform

\section{Introduction}

Nowadays, whether in China or in other countries of the world, natural resource is not only an important part of the ecological system, but also the material foundation, spatial carrier and key element of ecological civilization construction, supporting all walks of life and affecting all future generations. Faced with the severe situations of tight resource constraints, severe environmental pollution and degraded ecosystems, in 2012, the 18th National Congress of the Communist Party of China raised the construction of the ecological civilization to an unprecedented political height by incorporating it into the five-sphere integrated plan for building socialism with Chinese characteristics. It is clearly proposed to vigorously promote the construction of the ecological civilization and strive to build a beautiful China. In 2015, China made systematic arrangements for the natural resource management system by adopting the Integrated Plan for the Reform of the System for Developing an Ecological Civilization. In 2017, the 19th CPC National Congress proposed that man and nature are the community of life. Only by following the laws of nature can mankind effectively prevent detours in the development and use of nature. Harm to nature will eventually hurt mankind themselves. This is the law which we cannot resist. The reform of the system for developing an ecological civilization is overall, fundamental and strategic. The reform of the natural resource management system has a very important status and role in the entire reform of the system for developing an ecological civilization. The importance and urgency of the reform of the natural resource management system must be fully grasped. Deepening the reform of the natural resource management system and establishing a systematic and complete management system are 
the intrinsic requirements for the construction of ecological civilization in China and a strategic choice for realizing the Chinese Dream of the National Rejuvenation.

\section{International Trends in the Reform of Natural Resource Management}

\subsection{Institutional Construction Has Become an Important Measure for Developed Countries to Deal with the Issues of Resources, Environment and Ecological Security}

The "Tragedy of the commons" Theory is the theoretical foundation for the reform of the property rights system [1]. Due to the fact that natural resources do not have exclusive property rights, the excessive use of resources has led to serious damage to the ecological environment, triggering a major discussion on the protection of the property rights of natural resources in the international community. Developed countries have established laws and regulations on resource ownership, use, income and disposition of resources, established a sound natural resource property system [2], and used the balance sheet as a means of asset management [3], which is the basis for implementing the paid usage for resources. As a tool of governmental management of space, spatial planning has also increasingly emphasized the construction of a comprehensive spatial planning system covering the entire area based on the resource environment survey and evaluation. For example, the EU's comprehensive spatial planning promotes the comprehensive rectifications of land and space and comprehensive management of the ecological environment through the comprehensive optimization and allocation of various resource elements. This will play a key role in the coordination and guidance of the EU's sustainable development. Strict land use control is a common practice in most countries of the world and is an important means to achieve the natural ecological space protection and rational use. The market-oriented allocation of resources, paid usage and internalization of damages are important means overseas for the promotion of resource conservation and ecological protection. These have also formed a more mature approach. Comprehensive natural resources legislation has become an important choice for major powers to strengthen the reform of natural resource management because of its unique filling, coordinating, guiding and promotional features. For example, the U.S.'s National Environmental Policy Law and Russia's Natural Environmental Protection Law are all comprehensive resource and environmental laws. From the macro perspective, legal adjustments have been made to the resources and environment to ensure the rational use and effective management of natural resources. With the increasing amount of natural resource information data, its function to promote the economy is increasing and the role of the natural resource information in social management is becoming increasingly diversified and has become an important social public service. Therefore, the natural resource information management system has also become a basic natural resource management system for resource-rich countries.

\subsection{Comprehensive Management Based on Classification Is the Basic Direction of the Natural Resources System Reform}

Since World War II, developed countries have made major adjustments to the natural resource management system which has displayed a comprehensive management trend on the basis of resource classification management. Since the 1990 s, driven by the revolution in information technology, the government's self-innovation campaign, guided by such theories as the overall government, the government of coordination, integration of several ministries into a large ministry and new public services, has become prevalent throughout the world [4-7]. It has positively promoted the reform of the traditional decentralized natural resource management system. This group of theories have emphasized the reduction in waste of governmental resources and coordination costs caused by the decentralization of past governance structures through a framework of institutional arrangements. The same category of services shall be concentrated on the same governmental department to realize the integration of a wide range of sectoral institutions. During the reform process, Russia, Canada, the United States, Brazil, Australia and other major resource-rich countries in the world have all adopted the institutional structure of "multi-categories integrated resource management". The scope of resource management has gradually widened in the horizontal direction, taking a moderately comprehensive road with multiple types of resources, a road of rational combination with the development of the resource industry and a road of the increasingly close relationship with the ecological management and protection. For example, the U. S. Department of the Interior, which is a highly comprehensive governmental agency responsible for managing many areas of natural resources and environment. By the same token, in the natural resource management systems of 50 states, 40 have adopted a relatively comprehensive natural resource management system.

\section{Outstanding Problems in China's Natural Resources Management}

At present, China is at the critical stage of the reform of the system for developing an ecological civilization. It is also the intensive period for the adoption of various reform policies. These policies will play extremely important roles in the protection, development, utilization, and protection of natural resources. However, in general, both the concepts of natural resource exploitation and utilization and the management institutions and systems have varying degrees of incompleteness and imperfection, thus, to a large extent, affecting the effectiveness of the reform policies of natural resource management systems. 


\subsection{The Concepts of Resource Development and Utilization that Adapt to the Requirements of Ecological Civilization Have Not Been Formed Yet}

Development concept influences natural resources development decision-making. In China, the long-standing view of the political achievements in terms of GDP has led to the blind pursuit of the economic growth by local governments. There is a widespread existence of "more focus on the material wealth (gold and silver mountains) and less focus on the environmental protection (lucid waters and lush mountains)" and the traditional production methods of high input, high consumption and high pollution have not been fundamentally changed. With the change, China's economic growth has paid a high price while achieving world-renowned achievements. Extensive use of resources and tightening of constraints are coexisting. Environmental pollution and ecological degradation seriously affect each other. Such ecological security problems as energy crisis, freshwater crisis, climate anomalies and species extinction frequently occur and become important obstacles to the construction of ecological civilization. The emergence of these problems is related to the lack of top-level planning, blind development and excessive exploitation. However, the ideological inertia of simply pursuing the economic growth is deeply entrenched. The development concept which deviates from the requirements of the Scientific Outlook on Development and blindly compares with each other has dominated the development direction of the region. Therefore, we must establish the concept of ecological civilization that respects nature, adapts to nature and protects nature.

\subsection{The Natural Resource Management System which Adapts to the Requirements of Ecological Civilization is Imperfect}

In China, the natural resource management system is an important part of the institutional system of ecological civilization. The three steps of strict prevention of the source, strict control of the process and strict punishment of severe consequences are lacking in management system measures to adapt to the requirements of ecological civilization. In terms of the source control, the property rights system of natural resource assets is still incomplete, the property rights of resources are not clearly defined, and the protection of the rights and interests of resources is not well implemented. The use control system has not covered all the national ecological space, resulting in inadequate protection of such resources as wetlands and tidelands; The system of laws and regulations is imperfect, the legislative fragmentation is existing, the laws and regulations are not complete and the comprehensive laws are missing. In terms of strict control of processes, resources are intensively conserved and utilized, scientific standards and evaluation mechanisms are missing. The government's intervention in resource allocation is strong, deep and wide-ranging in scope. The decisive role of the market has not been fully realized. There is no basis for economic rationality of the development, utilization and allocation of resources.
There is a lack of systematic and comprehensive rectification of the land space, resulting in the artificial fragmentation of the life community of mountains, water, forests, fields and lakes. In terms of severe punishment of serious consequences, there is no strict accountability and compensation system. It is difficult to effectively supervise the illegal exploitation of natural resources and allocation of resources beyond the authority of local governments. The rights order of natural resources property has not yet been formed and effective mechanism for dealing with disputes over natural resources is not sufficiently provided. Therefore, China needs to improve its natural resources management system along with the reform of the system for developing an ecological civilization.

\subsection{The Natural Resource Management System Adapting to the Requirements of the Ecological Civilization Has Not Been Established Yet}

The natural resource management institution is an important part of China's institution for developing an ecological civilization. The fragmentation of natural resource management, the resource management departments and environmental protection departments have overlapping functions in the development and utilization of resources, environmental protection and planning, standard formulation, supervision and implementation [8]. The boundaries are not clear, the institutions are duplicated and the connecting links are missing or dislocated. There is a lack of effective comprehensive coordination mechanisms among departments, which are individualized and diversified, highlighting the interests of departments and their own levels. The lack of protection of overall interests is a serious problem. In particular, the comprehensive decision-making departments are lagging behind in their response and the functional overlapping areas lack the ultimate decision-making mechanism, which brings about the phenomena of policies coming out of different governmental departments and self-governance based on their own free will, making it difficult to effectively realize the comprehensive benefits of resource management and affect the efficiency and effectiveness of the national natural resources management. It is imperative to establish an integrated and coordinated management system. China's resource supervision and management are not in place and it is easy to overlook one another in supervision. The chaos in the resource development and utilization is more serious and the development and utilization orders have not yet fundamentally improved. The management system of natural resource assets is not perfect. The loss of earnings from natural resources assets owned by the public is quite serious.

\section{Main Ideas and Institutional Framework}

\subsection{General Requirements}

Since 2012, Chinese Government has made a series of 
major policy decisions on the construction of ecological civilization, which has an important impact on the reform of the natural resource management system. This is one of the important bases for building a system of natural resources. The reform of the natural resource management system affects the overall situations of the reform of the system for developing an ecological civilization. The new requirements of the 18th National Congress of the Chinese Communist Party on vigorously promoting the construction of ecological civilization shall be fully understood and the overall deployment of the ecological civilization system construction since the Third Plenary Session of the 18th CPC Central Committee should be deeply grasped. The goal of the sustainable use of natural resources is to promote the transformation of resource management methods, development and utilization methods and focus on solving the outstanding issues in the resource sector, combining the central top-level design and specific practices in the field of resources and accelerating the establishment of a systematic and complete system. The system provides basic support for deepening the reform of the system for developing an ecological civilization and building a beautiful China.

\subsection{Basic Concepts}

In China, the reform of the natural resource management system must adhere to the basic concepts of the reform of the system for developing an ecological civilization and use them to guide the reform. Adhere to the harmonious development concept of man and earth, establish the concepts of respecting nature, adapting to nature, protecting nature and realize the sustainable development of the Chinese nation; Adhere to the unified development concept of development and protection and establish the concept of owning both the material wealth (Gold and Silver Mountains) and the environmental protection (Lucid Waters and Lush Mountains), Lucid Waters and Lush Mountains Are Invaluable Assets to realize the unification of natural capital and natural value; Adhere to the concept of systematic development and establish the concept of mountains, waters, forests, fields and lakes as a life community to realize the comprehensive management of the ecological system; Adhere to the development concept of process management and establish the whole process management concept of "source protection, process conservation and terminal governance" to realize the beautiful Chinese Dream; Adhere to the principle of classified management and the direction of integrated management (Figure 1), establish the concept of natural resource classification management to realize the smoothness of the natural resource management system[9].

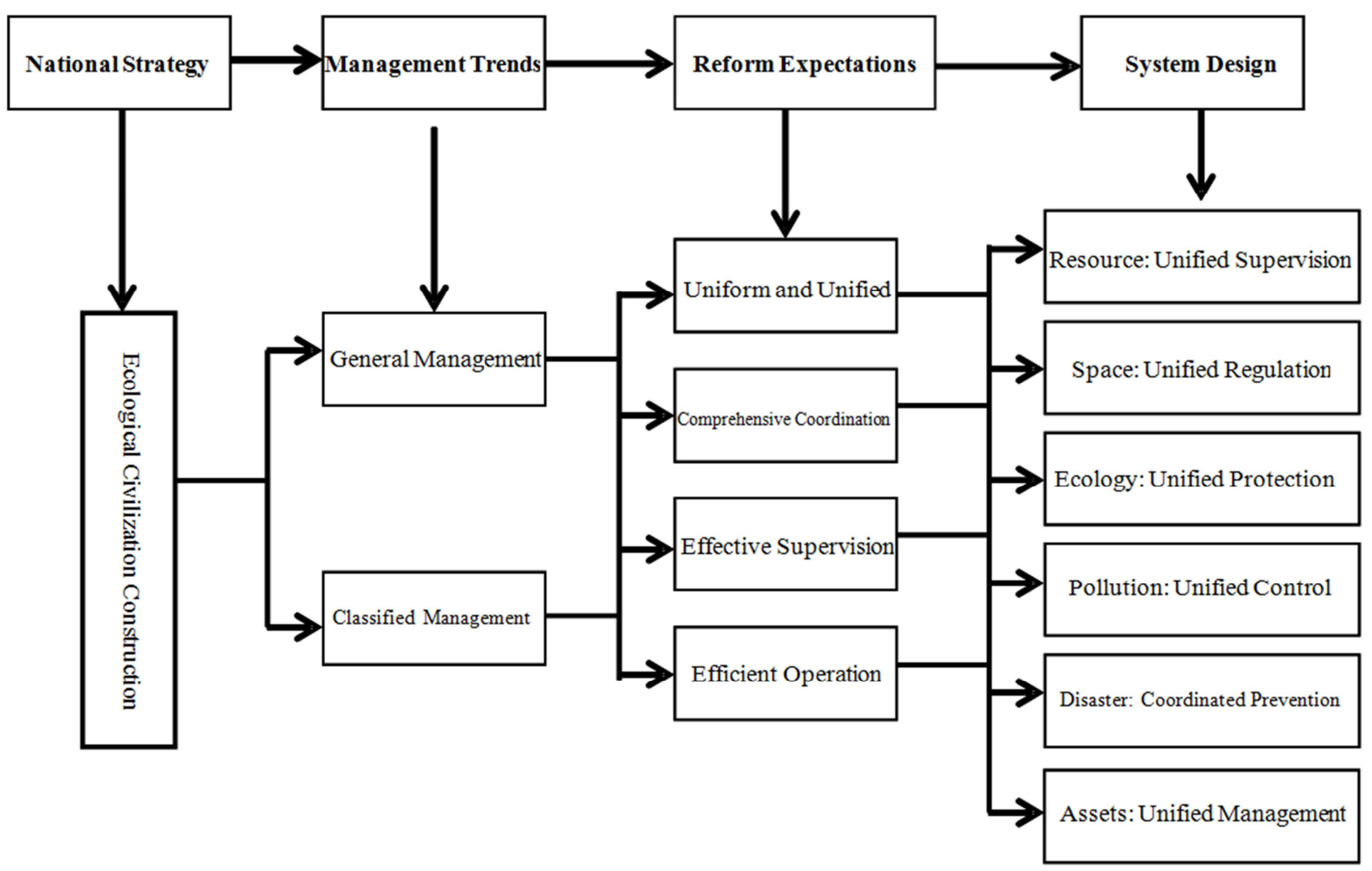

Figure 1. Thought on the Reform of Natural Resource Management System.

\subsection{System Framework}

According to the prominent issues faced by China's natural resource management and the understanding of some experts and scholars[10], we believe that the natural resource management system shall be composed of "Two Major Foundations, Three Major Links and Four Major Guarantees" (Figure 2). 


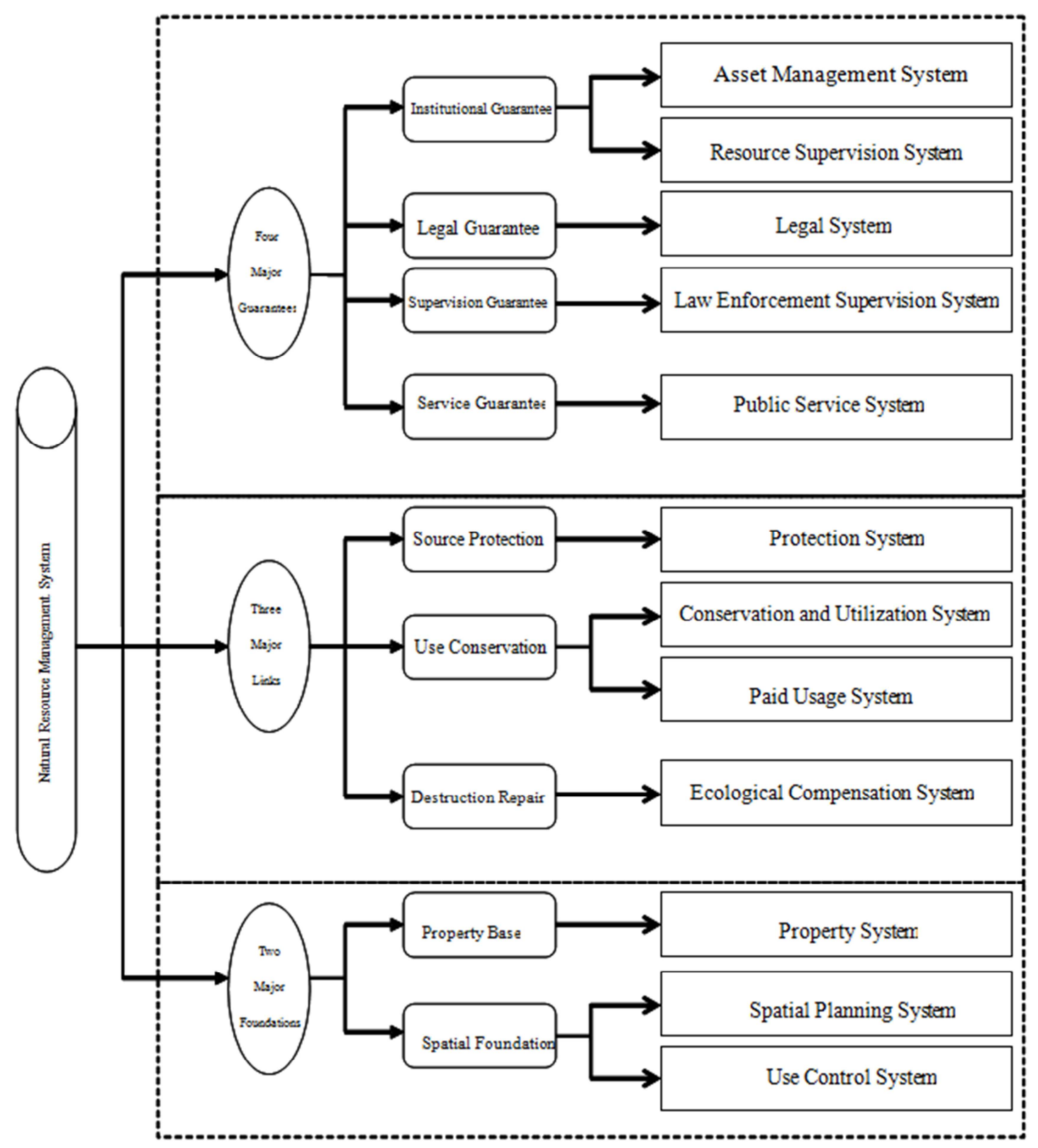

Figure 2. Natural Resource Management System Framework.

The property rights system and spatial planning (including use control systems) are the two basic systems in the natural resources system. The property rights system is not only the core system for the exploitation and utilization of natural resources, but also the basic system for the construction of ecological civilization. It permeates the entire process of the ecological civilization construction. Perfecting the property rights system of natural resource assets is not only the fundamental task of strengthening the construction of ecological civilization, but also the core of implementing the paid usage system and market resources allocation. Spatial planning is the basis of use control. The establishment of a unified spatial planning system is conducive to exerting the use control functions for planning purposes, standardizing the order of the national land spatial development, eliminating conflicts among spatial planning departments and promoting innovation in the planning system [11]. Use control is an important means to optimize the spatial development pattern of the national land. To improve the use control system is conducive to solving the problems of arbitrarily changing the use of natural ecological space and failure of the use control system to cover all the land space.

"Source protection, utilization conservation, destruction and restoration" are the three core links in the natural resources system. They are the key measures for the construction of an ecological civilization and a fundamental solution to beautiful China. Source protection is the primary strategy for maintaining national resource security and ecological security. Using conservation is the basic means to improve resource utilization efficiency and protect the 
ecological environment. Destruction and restoration are an important means to protect resources and promote the ecological restoration.

Institutional guarantees, legal guarantees, supervision guarantees and service guarantees are the four magic weapons in the natural resources management system. Service guarantee is the basis for promoting the transformation of government functions. The legal system is the legal guarantee for advancing reforms and consolidating the achievements of the natural resource reforms. Supervision management is a powerful guarantee for strengthening the protection of natural resources and fulfilling the accountability for natural resource damages. The management system is the fundamental policy to rationalize the regulatory structure of natural resources.

\section{Consolidate the Important Foundation of the Natural Resource Management System}

\subsection{Perfecting the Property Rights System of Natural Resource Assets}

In China, perfecting the natural resource property system is the core of natural resource asset management. Perfecting the property rights system of natural resource assets should address such issues as unclear attribution of ownership, unclear rights and responsibilities, inadequate protection of property rights, unsmooth property rights transfer, difficulty in the implementation of the owners' rights and imperfect property rights system [12-13]. The building of the property rights system of natural resource assets featured by clear attribution of ownership, clear rights and responsibilities, smooth property rights transfer and strict protection of the property rights has enabled the market to play a decisive role in the property rights allocation of natural resource assets and form a diversified, multi-level system of property rights for natural resource assets. First, establish a unified registration system for property rights confirmation. In 2017, seven departments including the Ministry of Land and Resources of the People's Republic of China formulated the Measures on the Use Control of Natural Ecological Spaces (Trial Implementation). The Measures shall be implemented as an opportunity to conduct a unified registration of all such natural ecological spaces as water currents, forests, mountains, grasslands, unreclaimed land and tideland for confirmed rights, setting clear definitions of the property ownership subjects of all types of natural resources assets of all national land space, gradual demarcation of the boundary between the public ownership and the collective ownership, drawing of the boundary between the public ownership and the ownership executed by different levels of government and drawing of the boundaries among different collective owners. Accelerate the trial of the unified registration of natural resources for confirmed property rights to create replicable and scalable experiences. Second, improve the property rights system of natural resource assets. It shall clarify the representatives of the ownership entities of all publicly-owned natural resources assets, specify the terms of reference for authorized relevant functional departments to exercise the public ownership, implement the ownership status of collective ownership of natural resources, promote the complete separation of ownership from usage rights, clarify the rights attribution and accountability of possession, use, income and disposal, etc. and appropriately expand the transfer, lease, mortgage, guarantee and paid-in equity of the right to use. Third, improve the system of protection of the property rights of natural resource assets. Respect and safeguard the legitimate rights and interests of people using the natural resources. Under the conditions of use control and legal provisions, protect the autonomy of people using the natural resource and allow the natural resource users to reasonably develop and use the resources in accordance with the specific conditions of natural resources. No administrative intervention may be used to interfere with its legitimate production and business activities. Fourth, explore ways to solve the problem of collective ownership of land in national parks. For the collective land in the national park, the land ownership may be adjusted by way of expropriation, transfer and agreement, or the land use may be prescribed in the form of an easement.

\subsection{Building a Unified Spatial Planning System}

A unified spatial planning system is the fundamental basis for the layout of national land development and productivity, affecting the overall situations of ecological civilization construction. Over the years, China's "divided policies from various sources" national land spatial management system has fragmented the integrity of production space, living space and ecological space, resulting in contradictions in the spatial orientation of the national land in China and affecting the improvement of the spatial efficiency of the national land [14-15]. This has caused adverse impact on the construction of ecological civilization. The establishment of a unified spatial planning system shall be based on the overall situations of the ecological civilization construction, firmly establish the vision of innovative, coordinated, green and open development that is for everyone, clarify the construction space, protection space and renovation space, promote the coordination of production space, living space and ecological space as well as the optimization of the spatial development pattern of the national land, and the ecological space will be beautiful, the production space will be intensive and highly efficient and the living space will be moderately suitable for living. In 2017, the Chinese Government formulated the Pilot Plan for Provincial Space Planning. To establish a unified spatial planning system, based on the implementation of the Plan, we shall use the national land planning as a basis to guide all kinds of spatial planning, and based on this, we can realize the integration of such relevant spatial planning as the overall land use planning, urban and rural construction planning. It forms a national land spatial planning system with full coverage of the entire area, clear 
positioning, complementary functions, linkage and coordination and orderly management and control [16].

\subsection{Perfecting the National Land Space Use Control System}

The use control system is the core system of the natural resource management system, but it has not yet covered all the land space. Although China has established strict control over the use of cultivated land and relatively strict control over the use of forest land, natural ecological spaces such as water areas, mountains, grasslands, unreclaimed land, sea areas and tideland have not yet fully established use control systems. In some areas including mountains, forest lands, wetlands and lake, the development and destruction of lakes and other phenomena still exist in large numbers. The control system for the use of forest lands is still not perfect. Some local forest lands have been altered for use or illegally occupied. The phenomenon of forest land loss and serious destruction of forest resources [17] has led to further deterioration of ecology in some areas. In this regard, focusing on the implementation of the Regulations on the Use of Natural Ecological Spaces (Trial), the following work was highlighted: First, speed up the establishment of a unified land and space planning system and reinforce the foundation of the use control system. Second, on the basis of the land use control system, use control will be extended to all natural ecological spaces such as woodlands, grasslands, rivers, lakes, wetlands, sea areas, and tidelands, and it is forbidden to change their use. Third, establish a permit system for the exploitation of natural resources and a system of approval for diversion of use, strictly protect natural resources, and strictly control arbitrary development behavior.

\section{Strengthen Key Links of the Natural Resource Management System}

\subsection{Perfecting the Source Protection System}

To protect natural resources is to protect the ecological environment, that is, to protect productivity. Based on resolving natural resources management, re-development of light protection and resource protection to avoid such problems [18-19], it is necessary to establish the concept of source protection, and improve and perfect the source protection system of natural resources with clear responsibilities. First, establish an ecological red line protection system to classify the ecological land that is of great value for the protection and restoration of regional ecological functions as an ecological red line and implement special protection. Second, improve the three-sphere integrated system for quantity, quality, and ecology of cultivated land protection. Implementing the strategy of "collecting grain at the land and storing grain for technology", continuing to push forward the construction of high-standard farmland on a large scale, accelerating the demarcation of permanent national basic farmland, and consolidating the foundation for national food security; establishing a new mechanism for balance management of cultivated land compensation, in accordance with the concept of "occupation control, mode adjustment, calculation of large accounts and differentiation", improving and standardizing the policy of compensating balance; comprehensively promoting the construction of soil stripping and utilization systems for cultivated land occupied by cultivated land, and constantly exploring stripping technology methods and soil utilization modes. Third, implement a protection system that combines development and protection with respect to mining development, and promote the construction of green mines in accordance with the ideas of development and surface protection. Fourth, in accordance with the integrity of the river basin management system, we must adhere to the principle of government management, land management, and divisional responsibility, and the departments should collaborate and co-govern in order to build a protection mechanism for rivers and lakes. The combination of basin management and administrative area management should be used to build the five-level "river-long" organizational system at the province, city, county, township and village levels to promote the healthy development of rivers and lakes. In addition, it is necessary to actively build a national space development protection system, improve the supporting policies for China's main functional areas, and establish a natural protection system with the national park as the main body.

\subsection{Perfecting the Economy and Intensive Use System}

Saving resources is the fundamental policy for protecting the ecological environment. In order to promote the economical and intensive use of natural resources, relevant departments of the state have done a lot of work in terms of planning plans, quota standards, assessments and other aspects. Although a preliminary institutional framework has been formed that is conducive to the intensive use of natural resources, it meets the requirements of the Central Government. However, there is still a certain gap, which is mainly manifested in: lack of adequate planning and control of economical and intensive use of resources, outbreak of urban construction planning that breaks through the overall land use planning; and lack of legal constraints in the natural resources conservation and intensive system, and no clear planning for breakthroughs. Legal responsibility for planning, standardization, extensiveness, idleness, waste, etc.; the degree of marketization of resource allocation is low, and the price mechanism reflecting the degree of resource scarcity, supply and demand, and environmental damage has not yet taken shape; relative lack of intensive standards for natural resource conservation and resource coverage. The standard system for the development and utilization of the entire process has not yet been established; the incentive-restraint mechanism for economizing on intensive use has no substantial impact. In this regard, the most stringent natural resources conservation and intensive utilization system 
should be improved and implemented in accordance with the idea of "planning and control, strict access, incentive and restraint, evaluation and assessment, and strengthening of supervision". First, strengthen the role of resource planning guidance and control. Strengthen the constraint effect of planning on the use of natural resources, strictly implement total quantity control and maintain the authority and seriousness of planning. Second, improve the system of resource conservation and intensive use of access. The natural resource property relationship will be taken a detailed look, improving the market system and optimizing the allocation of resources. Meanwhile, a number of urgently needed standards and specifications will be quickly developed to improve resource development and access thresholds. Third, establish a market-based resource pricing mechanism. Actively promote the market-oriented reform of natural resource prices, and gradually establish a scientific price formation mechanism that can reflect the scarcity of natural resources, market supply and demand, and environmental governance costs for pollution. Fourth, improve the resource conservation and intensive use of incentive and restraint mechanisms. Scientifically use economic levers such as "price, tax, fee, and gold" to fully mobilize the enthusiasm of enterprises and society for resource conservation. Fifth, improve the assessment mechanism of economy and intensive use. We will formulate an assessment system to improve the implementation of the plan, the efficiency of resource utilization and the construction of an economical and intensive utilization system, which will be included in the resignation audits of local leaders at all levels.

\subsection{Perfecting the Paid Usage System}

The paid usage system is an important way to play a decisive role in the allocation of resources in the market and to increase the level of resource protection and rational utilization. Although significant progress has been made in the construction of the paid usage system for natural resources in China, there are still unsound institutions, inconsistent property rights systems, imbalanced development of various types of resources, insufficient institutional effectiveness and efficiency, unreasonable interest mechanisms and imperfect supervision. Problems, to a certain extent, lead to serious depletion of natural resources and the deterioration of the ecological environment. The focus of the reform should be based on the following aspects: First, cancel the dual-track system for land supply. Expand the scope of paid usage of state-owned land and gradually narrow the scope of non-public welfare land use. Except for special land, such as military, national defense and social security housing, all types of construction land will be based on paid usage fees. The establishment and improvement of the paid transfer system for unused land shall be clearly defined. The preconditions for the development of unutilized land do not involve changing the nature of the land type, and land is provided by leasing in principle. Second, strictly control the transfer of mineral resources agreement, improve the allocation of mining rights to set up management methods and greatly increase the transfer proportion of competitive mining rights. Third, clarify the scope of paid usage of water, forests and grasslands. Differentiate the operational water from public welfare water use, focus on exploring the establishment of a paid usage system of landscape assets for state-owned forest resources and strictly define the scope of paid use of all the publicly owned grassland resources. Fourth, improve the paid use of natural resources and regulate the transfer of income management.

\subsection{Perfecting the Ecological Compensation System}

The ecological compensation system is an important means to promote ecological restoration. The ecological restoration and compensation system in China is still incomplete in terms of compensation scope, compensation standards, compensation methods and management systems, which affects the effectiveness of the implementation of the ecological environmental protective measures to a certain extent [20-23]. To improve the ecological compensation system, we should use the Opinions on Perfecting the Ecological Protection Compensation Mechanism formulated by the Chinese government to scientifically define the rights and obligations of the ecological protectors and beneficiaries, accelerate the formation of ecological damages, compensate the beneficiaries and protect the reasonable compensation mechanism. First, speed up the establishment of an ecological compensation system and continue to explore ways of compensation, compensation standards, compensation methods, etc., and gradually form a pattern of interest adjustment of "whoever develops and protects benefits and compensates". Second, establish a regional cross-regional ecological protection compensation mechanism to guide the ecologically beneficial areas and protected areas, improve resource consumption in resource-producing areas, upstream-downstream and eastern-western regions and gradually establish the ecological values and generational relationships. The compensated ecological compensation system promotes the saving of resources for the social subjects and protects the environment and uses the system of ecological compensation to ensure the construction of the ecological civilization. Third, gradually establish and improve the ecological compensation mechanism for key ecological areas, establish a system of ecological restoration guarantees, improve the system of mine geological environmental protection and land reclamation and form a long-term mechanism for comprehensive land consolidation and ecological restoration.

\section{Strengthen Core Guarantee of the Natural Resource Management System}

\subsection{Improving the Public Service System}

A sound and complete natural resources public service 
system is an effective complement to natural resource management. Although China's sub-sectoral natural resource public services are beginning to take shape, they are affected by fragmented resource management systems, and various types of public services are dominated by individual resource management departments. They lack comprehensive surveying, evaluation, development, and utilization services, causing too narrow range of public services and a low degree of social service. To improve the public service system for natural resources, the following should be highlighted: The scope and content of public services for natural resources should be expanded and enriched, improving the public service institutions for natural resources, perfecting the laws and policies on natural resources and public services, strengthening the construction of infrastructure and application platforms for natural resources and public services and realizing their networking and facilitation[24].

\subsection{Perfecting the Law Enforcement Supervision System}

The law enforcement supervision system is an effective means to curb ecological destruction and strengthen supervision. For a long time, China's natural resource law enforcement supervision system has been self-contained, relatively decentralized, lacking in comprehensive supervision and comprehensive coordination mechanisms and caused cross-sectoral difficulties in synergistic departments, high supervision and enforcement costs and low supervisory effectiveness. To reform the natural resources law enforcement supervision system, we must first formulate a comprehensive natural resource management law, further improve the status of supervision and management, integrate and optimize the supervision power of natural resources and achieve top-down management. Second, we must improve the means of natural resources law enforcement supervision, make full use of satellite remote sensing monitoring, electronic eye, Internet of Things and other modern information technologies, give full play to the advantages of big data [25], achieve regulatory data sharing and improve regulatory effectiveness.

\subsection{Perfecting the Legal System}

Legal system is an effective guarantee for the natural resource management system. After many years of exploration, although China's natural resource legal system has basically been completed, under new situations of ecological civilization construction, relevant laws and regulations still have varying degrees of "absence", "dispersal", "chaos", "old", " "soft" and other issues of varying degrees. The reform should focus on the following two aspects: first, steadily implement the revision of the laws on the property rights of individual natural resources [26]. Revision of various laws will be steadily pushed forward regarding the wetland legislation that lacks relevant laws in the current legal system and the specific contents and protective measures of the related property rights will be systematically specified. In particular, the Wetlands
Protection Act or Regulations on Wetland Protection should be drafted on the basis of the local regulations on wetland protection that have already been issued in some provinces and cities. Second, in-depth development of comprehensive legislation on natural resource property rights [27]. Laws such as the Rural Land Contract Law, Urban Real Estate Management Law, and Land Management Law have been consolidated to form basic laws for the management of land resources. Taking the drafting of the Civil Code as an opportunity to reorganize the system of property rights related to natural resources and explore the comprehensive legislation on natural resources.

\subsection{Steadily Promoting the Reform of Management System}

The reform of the natural resource management system is a long-term process that should be steadily advanced and cannot be achieved overnight. In China, since the establishment of the Ministry of Land and Resources in 1998, although centralized management of land, minerals, marine resources and geographic information for surveying and mapping has been centralized and unified, it is difficult for multiple sources of management, overlapping of powers and functions and management fragmentation to satisfy the need for the reform of the system for developing an ecological civilization [28]. In March 2018, the 13th National People's Congress of China which has just been concluded reviewed and approved China's State Council's institutional reform program and proposed the formation of the Ministry of Natural Resources for the unified exercise of the public ownership of all the natural resources assets and the unified exercise of all national land use controls as well as the responsibility for the restoration of ecological protection. At present, efforts should be made to promote the reform of the natural resource supervision system and the natural resources asset management system. First, improve the natural resources regulatory system. First, based on national land planning, establish a unified spatial planning system. The separation of planning responsibilities of the organization's main functional areas originally distributed in the National Development and Reform Commission, the responsibility for the preparation of urban and rural planning and management by the Ministry of Housing and Urban-Rural Development, and the newly established Natural Resources Department shall exercise the responsibility for the preparation of space planning and supervise the implementation of relevant departments. On this basis, based on the integration of land use control responsibilities, relevant land supervision duties are separated from other resource management departments, and are uniformly exercised by the Ministry of Natural Resources, and formed on the basis of national land planning and use control as a means to exercise, in union, the supervision of land resources in all land and space, unified protection and unified restoration of lakes and grassland in the mountains and forests. Second, improve the natural asset management system. A relatively independent Natural Resources Assets Administration Bureau is established under the Ministry of Natural Resources of China to fulfill the responsibilities of owners of all types of natural resources assets of the entire 
nation and establish a paid use system of natural resources. To explore the system of ownership of all natural resource assets owned by the central government and local government agencies, and to clarify the relationship between the responsibility and rights of the central and local governments in the natural resources asset management system, and the relationship between authority and financial power.

\section{Conclusion}

The proposed paper introduces the progress of China's ecological civilization construction and the development of natural resource management system. Problems of China's natural resource management are reviewed, including inadequate government institution, backward concepts and incomplete management rules. The comparison between China and other countries has been made, providing evidence and experience for China's further reform.

This paper suggests detailed insight to the procedure for the reform of natural resource management. Theoretically relevant information as well as systematic application of the institutional framework is transparently given. Suggestions of consolidating the important foundation of natural resource management, strengthening key procedures of natural resource management system and well as ensuring the core guarantee measures are provided.

To summarize, the designated reform paths of natural resource management system with the target to realize the smooth process of natural resource management suggests a suitable and adoptable way for China's natural resource management reform.

\section{Acknowledgements}

We thank the Project of Key Bottlenecks of Resources and Environment in a Century of Power (Y7X0561601) for financial support.

\section{References}

[1] Hardin. The tragedy of the commons [J]. Science, 1968, (162): 1243-1248.

[2] Ma Yonghuan, Chen Liping, Shen Lei, Gu Shuzhong, etc. International Progress and Key Recommendations of Natural Resource Asset Management [J]. Land and Resources Information, 2014, 12:1-8, 22.

[3] Feng Zhiming, Yang Yanzhao, Chen Yue. Progress in Research on National Balance Sheets and Its Implications for the Preparation of Balance Sheets for Natural Resources. Resource Science, 2015, 37(9):1685-1691.

[4] Tom Christensen. Post-NPM and Changing Public Governance [J]. Meiji Journal of Political Science and Economics, 2012, 1 (1):1-11.

[5] Perri 6, et al. Towards holistic governance: the new reform agenda [M] New York: Palgrave, 2002.
[6] Tom Christensen, Per Lagreid. The Whole-of-Government Approach to Public Sector Reform [J], Public Administration Review, 2007, 67, Issue 6.

[7] Kirk Emerson, et al. An Integrative Framework for Collaborative Governance [J], Journal of Public Administration Research and Theory, 2012, 22, No. 1.

[8] Project Group of the Second Division, SCOPSR. The Initial Thinking on Improving the Natural Resources Management System [J]. China Institutional Reform and Management 2016, 5:29-31

[9] Gu Shuzhong, Li Weiming. Natural Resources Asset Management Reform Needs to Handle Ten Pairs of Relationships [N]. China Economic Times 2016-1-8. 7th Edition.

[10] Yang, Weimin. Establish A Systematic System of Ecological Civilization [N]. Guangming Daily, 2013-11-23.

[11] Ma Yonghuan, Li Xiaobo, Chen Congxi, etc. The Idea of Establishing A Unified National Spatial Planning System [J]. China Soft Science Magazine 2017, 3: 11-16.

[12] Ma Yonghuan, Liu Qingchun. Strategic Thinking on China's Natural Resource Property System Construction [J]. Bulletin of Chinese Academy of Sciences 2015, 30(4): 503-508.

[13] Chen, Xiaohong. The Establishment of an Ecological Civilization Institutional System Focuses on Improving the Natural Resources Assets Management System [N]. REDNET. CN, 2013-12-11.

[14] The Sustainable Development Strategy Research Group of Chinese Academy of Sciences. 2015 China Sustainability Report - Reshaping Eco-Environmental Governance System [M]. Beijing Science Press, 2015.

[15] Yang, Yinkai. The Background and Framework of the National Spatial Planning System [J]. Reform 2014, 8: 125-130.

[16] Li Yuehan, He Jia, Bao Cunkuan. Overlapping Responsibilities of China's Current Spatial Planning and the Urgent Need for Correct Handling the Four Major Relationships: An Analysis Based on the Overall Plan for the Reform of the Ecological Civilization System [J]. Shanghai Urban Management, 2016, 1: 10-14.

[17] Qi Fan, Li Xianwen, Liu Kang. Study on the System of Natural Ecological Space Use Control [J]. China Land 2016, 12.

[18] Wang, Min. Considerations on Deepening the Reform of Natural Resource Management System [J]. China Leadership Science, 2016(10):30-33.

[19] Zhao, Qingqing. Research on the Reform of Resource-Based State-Owned Assets Management System [D]. Changchun: Jilin University, 2014:18-22.

[20] Deng H, Zheng P, Liu T, et al. Forest ecosystem services and eco-compensation mechanisms in China[J]. Environmental management, 2011, 48(6): 1079-1085.

[21] You, Yanxin. Research on China's National Ecological Compensation System [D]. Tianjin: Hebei University of Technology, 2007.

[22] Department of Nature Conservation, National Environmental Protection Agency. Theory and Practice of Ecological Environment Compensation in China [M]. China Environmental Science Press, 1995. 
[23] Ding, Sibao, etc. Research on Ecological Compensation of Main Function Zones [M]. Science Press, 2009.

[24] Bychkov, I. V., Nikitin, V. M. Water-level regulation of lake Baikal: Problems and possible solutions [J]. Geography and Natural Resources, 2015, 36(3): 215-224.

[25] Chenglin Miao, etc. Natural resources utilization efficiency under the influence of green technological innovation [J]. Resources, Conservation and Recycling, 2017, 126 (11): 153-16.

[26] Max Harleman, Jeremy G. Weber. Natural resource ownership, financial gains, and governance: The case of unconventional gas development in the UK and the US [J]. Energy Policy, 2017, (111): 281-296.
[27] Suresh ChandraBabu, etc. Integrating environmental considerations in the agricultural policy process: Evidence from Nigeria [J]. Environmental Development, 2018, (25): 111-125.

[28] Zebene Lakew Teffera, etc. Assessing land use and land cover dynamics using composites of spectral indices and principal component analysis: A case study in middle Awash subbasin, Ethiopia [J]. Applied Geography, 2018, (96): 109-129. 